\title{
Perfil glicêmico de cabras leiteiras gestantes criadas na microrregião do Cariri Ocidental Paraibano
}

Marcelo Laurentino dos Santos Junior, Laura Honório de Oliveira, Luiz Gonzaga Dantas de Oliveira Campos Neto, Giulia Ferreira Souza Ricaldi, Antônio Fernando de Melo Vaz, Eldinê Gomes de Miranda Neto

Centro de Saúde e Tecnologia Rural, Hospital Veterinário, Universidade Federal de Campina Grande (UFCG), Patos, PB, Brasil

*Autor correspondente

e-mail: junior.vetmed@gmail.com

\section{Resumo}

A glicose é um metabólito importante na metabologia e fisiologia de ruminantes, principalmente quando ocorre elevada demanda da mesma para atender as necessidades orgânicas, produtivas e reprodutivas. Isto é notório durante o período de transição de cabras leiteiras, onde o excesso/carência de glicose pode resultar em doenças metabólicas e da produção. Dessa forma, foram avaliadas 11 cabras leiteiras das raças Toggenburg (quatro) e Parda Alpina (sete) de um capril localizado no município de Serra Branca, localizado na microrregião do Cariri Paraibano, região de destaque para caprinocultura leiteira regional. Os animais eram submetidos a regime intensivo, alimentadas com milho em grão, milho moído, farelo de soja, farelo de trigo e torta de algodão (20\% cada) (ingestão média de 600 g/animal/dia), e volumoso composto por pastagem nativa e palma forrageira (Opuntia ficus-indica). As cabras foram selecionadas através de ultrassonografia (Aquila PRO, Esaote Piemedical ${ }^{\circledR}$ ) para identificar a gestação e posteriormente foram avaliadas nos momentos: T(-2): de 20-14 Dap (dias antes do parto); T(-1): de 13-1 Dap; T(0): no dia do parto; T(1): de 1-13 Dpp (dias pós-parto); T(2): de 14-22 Dpp e T(3): de 23-34 Dpp. Nestes momentos, eram colhidas em jejum, via jugular, amostras de sangue $(5 \mathrm{~mL})$ em tubos a vácuo contendo fluoreto de sódio (Vacutube ${ }^{\circledR}$ ), com plasma obtido através de centrifugação $3000 \mathrm{rpm} / 15 \mathrm{~min}$ e armazenado em microtubos em temperatura a $-20^{\circ} \mathrm{C}$ para posterior análise. Utilizou-se para mensuração kit comercial glicose hk (GLUC2) (Roche ${ }^{\circledR}$ ), empregado em analisador bioquímico automático Cobas c111 (Roche ${ }^{\circledR}$ ). A média de glicemia de T(-2) apresentou 81,35 $\pm 13,92 \mathrm{mg} / \mathrm{dL} ; \mathrm{T}(-1): 83,33 \pm 22,73 \mathrm{mg} / \mathrm{dL}$; e T(0): 102,26 $\pm 28,79$ mg/dL. Já T(1), T(2) e T(3) apresentaram médias de glicose de 98,09 \pm 14,61, 98,03 \pm 14,63 e 98,16 \pm 16,19 $\mathrm{mg} / \mathrm{dL}$, respectivamente, sendo todos os valores superiores aos de referência. Estes podem ser justificados pelo elevado teor energético da dieta, porém sem complicações ligadas ao excesso de carboidratos. Deve 
ser considerado o estresse principalmente no parto, o que induz hiperglicemia pela ação do cortisol e epinefrina (efeito gliconeogênico), além da possível resistência à insulina, maior no final da gestação e início da lactação. A mensuração da glicemia em cabras pode contribuir para adequações de manejo antes mesmo que distúrbios nutricionais e metabólicos possam interferir na produção. 